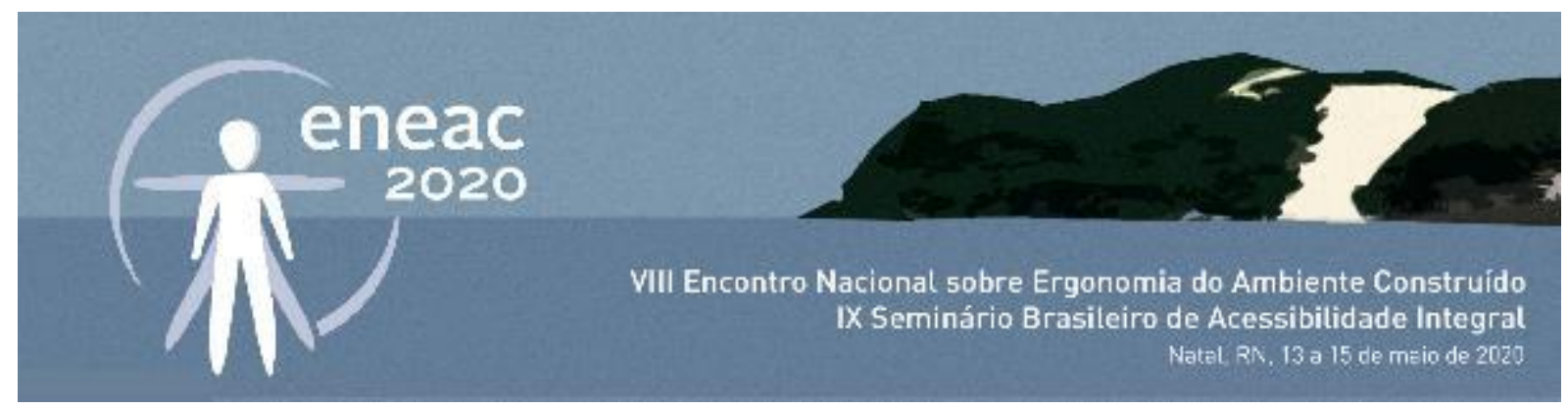

\title{
Arquitetura e autismo: orientações para espaços terapêuticos
}

\author{
Architecture and autism: guidelines for therapeutic spaces
}

\author{
GEOVANA DOS SANTOS ALOCHIO \\ Graduada, Faculdade Pitágoras, galochio@hotmail.com \\ VIRGINIA MAGLIANO QUEIROZ \\ Doutora, Faculdade Pitágoras, vimagliano@hotmail.com
}

\begin{abstract}
RESUMO
O grande aumento da população autista desperta o interesse de inúmeros pesquisadores da área da saúde, e um grande número de pesquisas foi e está sendo desenvolvido para compreender o Transtorno do Espectro Autista (TEA). Mas as crianças autistas lidam, diariamente, com inúmeros desafios que poderiam ser evitados ou, ao menos, amenizados, por meio da arquitetura. $O$ presente artigo investiga as características necessárias a um ambiente construído para que este possa auxiliar no desenvolvimento do indivíduo do espectro, contribuindo para seu crescimento pessoal e relacionamento com outras pessoas. Este estudo faz parte de um trabalho de graduação que surgiu como uma resposta à necessidade de projetar adequadamente um ambiente que proporcione melhores condições para o atendimento e suporte à população com TEA. Através da realização de uma revisão de literatura, consultando periódicos, artigos, teses, dissertações, livros e websites, buscou-se compreender a realidade desse grupo de pessoas e suas interações com o ambiente. Uniu-se à revisão a experiência prática de uma das autoras do artigo, mãe de uma criança de dez anos com TEA, gerandose diretrizes projetuais para ambientes terapêuticos que possam proporcionar melhores resultados no tratamento e desenvolvimento das pessoas com TEA. Conclui-se que a arquitetura pode ser mais humana, transitando na tênue linha entre o ser humano como indivíduo e sua capacidade de viver em sociedade.
\end{abstract}

PALAVRAS-CHAVE: Transtorno do Espectro Autista; TEA; diretrizes projetuais; elementos sensoriais; inclusão.

\section{ABSTRACT}

The great increase of autistic population turn on the interest of numbers of health researchers, and a large number of researches have been and are being developed to understand Autistic Spectrum Disorder (ASD). But autistic children deal, on a daily basis, with countless challenges that can be avoided or, at least, mitigated, through architecture. This article investigates the characteristics applicable in a environment built so that it can assist in the development of the individual on the spectrum, contributing to their personal growth and relationship with other people. This study is part of a graduate work that emerged as a response to the need to design, an environment that offers better conditions for the care and support to the population with ASD. Through a literature review, consulting journals, articles, theses, dissertations, books and websites, try to understand the reality of this group 


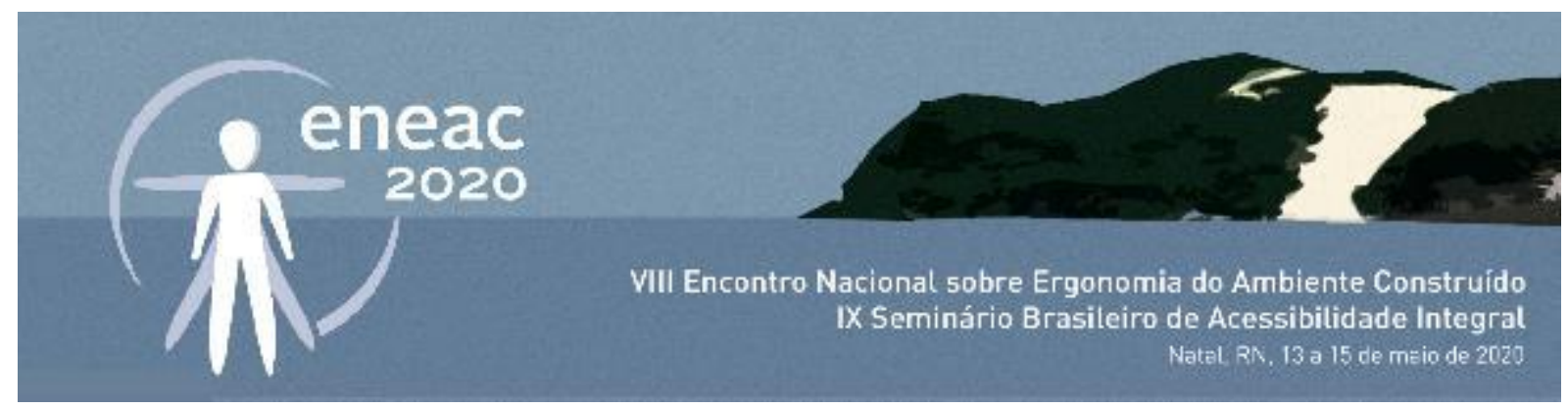

of people and their interactions with the environment. It joined the review of a practical experience of article authors, mother of a ten-year-old child with ASD, generating design guidelines for therapeutic environments that allow better results in the treatment and development of people with ASD. Conclude that architecture can be more human, moving on the line between the human being as an individual and his ability to live in society.

KEYWORDS: Autism Spectrum Disorder; ASD; design guidelines; sensorial elements; inclusion.

\section{INTRODUÇÃO}

Frequentar a escola regular é fundamental para as crianças do Transtorno do Espectro Autista (TEA), principalmente para sua integração social. Porém, a estrutura física e o método pedagógico das escolas tradicionais dificultam a inclusão das crianças do espectro. Elas se distraem ou ficam agitadas facilmente em ambientes com muitos estímulos, como é o caso das salas de aula (barulhos, excesso de cores e informações nas paredes), além de possuírem dificuldade de comunicação e aprendizagem.

É evidente a falta de preparo das escolas regulares para lidarem com esta situação, tanto pela falta de um ensino adequado, como de um ambiente apropriado para essas crianças. Diante deste cenário, é necessário buscar, precocemente, o auxílio de profissionais especializados que colaborem para o desenvolvimento cognitivo, comportamental, de habilidades cotidianas e de outras áreas indispensáveis (RUSSO, 2017).

Esta equipe multidisciplinar de profissionais estimula as habilidades necessárias para que as crianças do espectro possam ter, dentro de suas limitações, uma vida normal e independente. Mas as instituições que disponibilizam tais serviços muitas vezes não se atentam à influência do ambiente construído sobre o aprendizado, o comportamento e a integração social dessas crianças. Visando entender como o ambiente pode auxiliar o desenvolvimento das crianças do espectro autista surgiu a presente pesquisa, que procura responder a seguinte pergunta: Quais características ambientais influenciam no tratamento e desenvolvimento de crianças dentro do Espectro Autista?

Apesar de ser um tema atual, existem muitos estudos voltados para a origem do transtorno e como deve ser o ensino e o tratamento dessas crianças. Mas não existem tantas pesquisas que se dediquem à investigação de como as condições de um ambiente podem influenciar a vida de crianças e adultos, seja em casa, na escola ou no trabalho (AMA, 2017).

É esse o foco deste estudo, que surge como resposta à real necessidade de criação de um espaço planejado e projetado adequadamente, que proporcione melhores condições para o atendimento e suporte à população com o TEA. A presente pesquisa visa ainda ampliar os estudos sobre o transtorno na Arquitetura e no Urbanismo, incentivando novas pesquisas na área.

\section{METODOLOGIA}

A investigação voltou-se para o TEA e a influência que a arquitetura exerce no comportamento dos autistas, identificando as características que os ambientes devem ter para recebê-los da melhor 


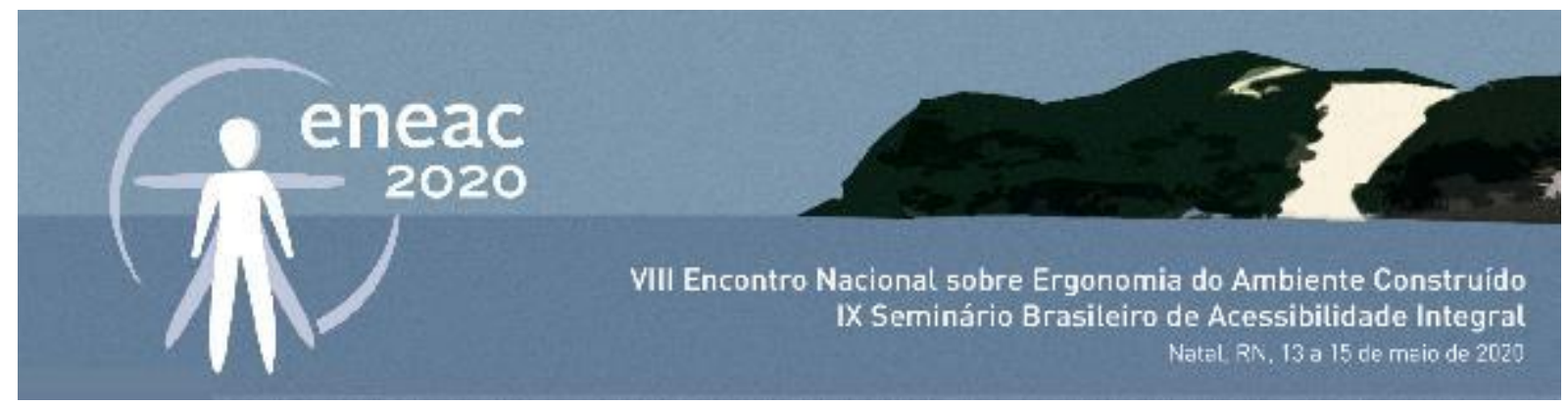

forma possível, incentivando seu desenvolvimento cognitivo. Para tanto foi realizada uma revisão de literatura por meio de periódicos, artigos, dissertações, teses, livros, manuais, relatórios e sites.

À revisão de literatura somou-se a experiência prática e vivência de uma das autoras do presente artigo, mãe de uma criança autista de nove anos de idade. Suas constantes visitas aos ambientes especializados no atendimento de crianças do espectro também agregaram conhecimento essencial para os resultados desse estudo.

\title{
3 O TRANSTORNO DO ESPECTRO AUTISTA (TEA)
}

O Transtorno do Espectro Autista (TEA) é um distúrbio geral do desenvolvimento que afeta o sistema nervoso central, normalmente se manifesta na infância e tem como principais características as dificuldades na comunicação e na interação social (MELLO et al., 2007).

\subsection{Definição}

Sendo o autismo um transtorno que se particulariza pelas variações de suas características desde idade muito precoce, normalmente antes dos três anos (MELLO et al., 2007), e possuindo um impacto grande e variável do desenvolvimento humano, sabe-se que ele não tem uma causa específica, embora a maioria das pesquisas apontem para a questão genética como o principal fator para seu desenvolvimento. Esta refere-se aos estudos relacionados à linha da genética que investiga o gene e não o código genético (DNA), que são os aspectos que atuam no crescimento do cérebro e na formação dos neurotransmissores (RUSSO, 2017).

\begin{abstract}
Suspeito que os pesquisadores simplesmente não entendem a urgência do problema. Eles não conseguem imaginar um mundo onde roupas que pinicam o fazem sentir-se pegando fogo, ou onde uma sirene soa como se alguém estivesse perfurando meu crânio com uma furadeira... (GRANDIN, 2015, p. 80).
\end{abstract}

De acordo com Russo (2017), além das suas manifestações principais como problemas sensoriais, atrasos na fala, comportamentos repetitivos e dificuldades na comunicação e interação social, outras questões de saúde podem se manifestar como hiperatividade, dislexia, transtorno obsessivo compulsivo (TOC), déficit de atenção, ansiedade e depressão. A Figura 1 apresenta o símbolo do autismo, representado pela fita composta por peças de quebra-cabeça coloridas, simbolizando o mistério e a complexidade do autismo. É um símbolo mundial da conscientização em relação a esta patologia, utilizada principalmente no Dia Mundial de Conscientização do Autismo.

Figura 1 - Fita quebra cabeça representando a diversidade do espectro autista.

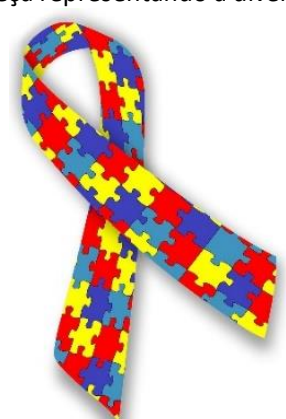

Fonte: https://www.dicionariodesimbolos.com.br/simbolos-autismo 


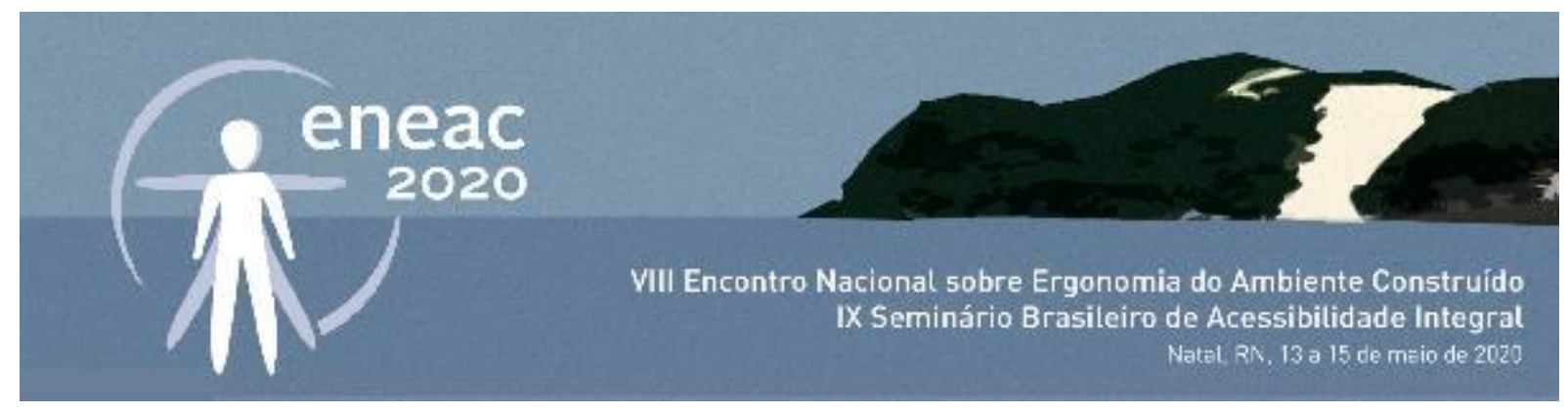

O transtorno denomina-se por espectro, pois há uma infinidade de variações de acordo com as características sensoriais, motoras e o desenvolvimento cognitivo de cada indivíduo. Existem os casos leves, conhecidos com Síndrome de Asperger, que não possuem deficiência intelectual e nem atraso na linguagem, tendo normalmente dificuldades somente na área da interação social. Mas existem também os casos mais severos, onde o autismo está relacionado a deficiência intelectual grave, com comportamentos repetitivos, grande déficit na interação social e atraso na linguagem, sendo muito comum nesses casos, o não desenvolvimento da fala oral (AMA, 2017).

Segundo a Associação de Amigos do Autista (AMA, 2017), o autismo pode ser classificado de três formas: Autismo Clássico; Síndrome de Asperger; e Distúrbio Global do Desenvolvimento sem outra especificação (DSD - SOE). O Autismo Clássico é o mais conhecido, e seus indivíduos podem apresentar grande variação no seu grau de comprometimento, envolvendo as diversas características em englobam o transtorno, como dificuldades em desenvolver o contato visual, comunicação verbal ineficiente, não usando a fala como ferramenta de comunicação adequada, sensibilidades exacerbadas ou diminuídas dos sentidos, movimentos repetitivos (estereotipados) e dificuldades na interação social de modo geral. Já a pessoa com Síndrome de Asperger normalmente possui particularidades como altas habilidades cognitivas, mas em contrapartida possuem problemas com habilidades sociais, dificuldades na motricidade fina e grossa, contratempos com jogos simbólicos, entre outros distúrbios. Se diferencia do autismo clássico, pois normalmente as pessoas que se enquadram nesse diagnóstico não possuem problemas para se expressar. Por fim, as pessoas que possuem o diagnóstico de Distúrbio Global do Desenvolvimento sem outra especificação (DSD SOE), são enquadradas dentro do TEA, mas têm seu diagnóstico dado com mais dificuldades, pois seus sintomas e características não são suficientes para serem incluídos em nenhuma das outras categorias específicas do transtorno.

\subsection{Tratamento}

Das informações disponíveis nas literaturas sobre o autismo e das pesquisas em andamento, a única certeza que se tem é de que ele não tem cura. Porém, sabe-se também que começar cedo o tratamento, intensificá-lo e adaptá-lo às necessidades da criança, melhora a perspectiva de um futuro de qualidade. Tendo o objetivo principal de potencializar as habilidades sociais e comunicativas deste indivíduo, diminuindo as características do autismo e a estruturação da assistência ao desenvolvimento e aprendizado da criança (AMORIM, 2020).

Amorim (2020) cita que não existe um tratamento padrão, uma vez que ele precisa ser direcionado às necessidades específicas de cada um, sendo necessário uma equipe experiente e com especialistas aptos a elaborar o programa para cada autista. De acordo com Amorim (2020) é fundamental que as terapias abordem os vários setores de desenvolvimento de um indivíduo, dentre eles:

comportamento e comunicação; fala e linguagem; terapia ocupacional; educação física; fisioterapia; e medicamentos.

Conforme Mello (2013), alguns dos métodos de tratamento que mais têm comprovação científica de êxito e conhecidos no mercado são: Treatment and Education of Autistic and Related Communication Handcapped Children (TEACCH); Picture Exchange Communication System (PECS); Applied Behavior Analysis (ABA); Floortime; e medicação.

O método TEACCH é baseado na coordenação do espaço físico, atendendo a rotinas e meios de trabalho, de modo a adequar o ambiente para deixá-lo mais compreensível para a criança, assim 


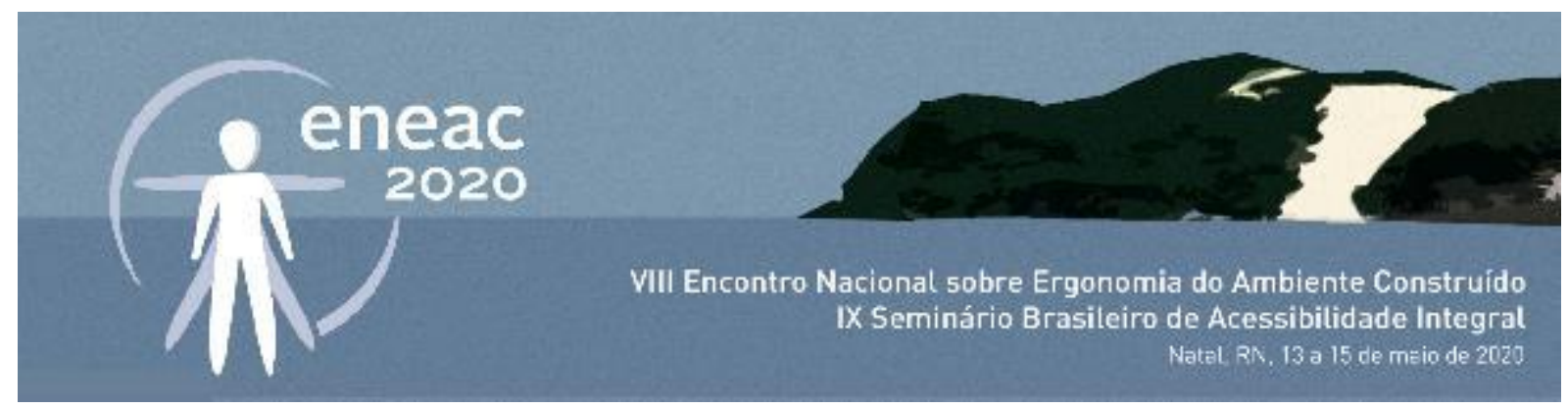

como captar o que se espera dela. Propõe-se a estimular a independência da criança, de maneira que ela necessite do professor apenas para o aprendizado. Mello (2013) ainda destaca que se esse método de tratamento for empregado corretamente, consegue-se resultados acima do esperado, consequências de um esforço demorado e voltado para as características individuais do portador da síndrome.

Já o PECS consiste em um método alternativo de trocas de figuras, de fácil aprendizado, não exige material caro, e pode ser trabalho em qualquer lugar. Se bem aplicado, apresenta excelentes resultados na comunicação dos autistas não verbais, e colabora com a coordenação da linguagem verbal em crianças que falam. Ainda influencia na percepção da criança que por meio da comunicação pode conseguir as coisas mais facilmente, estimulando-a a se comunicar mais, interferindo também na diminuição dos possíveis problemas comportamentais, decorrentes de uma comunicação falha.

O método ABA está fundamentado na análise aplicada do comportamento baseado no condicionamento funcional e reforçadores para incentivar comportamentos socialmente corretos, diminuir comportamentos indesejáveis. Mello e outros (2007) cita que se a resposta da criança for adequada às questões a ela propostas, ela tem como consequência algo que lhe seja prazeroso, o que na prática é uma forma de se recompensar. Respostas negativas, como birras, nãos e gritos não são reforçadas. Assim, a criança recebe os estímulos e aprendizados de forma agradável, evitando comportamentos indesejados. No desenvolver desse método, a repetição é relevante, bem como um diário das tentativas e seus resultados.

O Floortime, em português, "tempo no chão", se baseia no desenvolvimento funcional da criança, suas diferenças individuais e relacionamentos, tendo como objetivo a formação dos alicerces para as competências sociais, emocionais e intelectuais das crianças, ao invés de se focar em comportamentos isolados. Trata-se de uma metodologia de terapia ocupacional criada em 1990 pelo psiquiatra Stanley Greesnspan, que se baseia na interação com a criança autista através de brincadeiras que incluam um de seus pontos de interesse. É extremamente positiva, pois como toda criança brinca, autistas também devem desenvolver seu lado brincador, e precisam de ajuda para que esses momentos aconteçam (CLIA PSICOLOGIA, 2020). Essa terapia ajuda a estabelecer uma melhor conexão emocional e a partir dessa conexão é possível desenvolver uma comunicação de duas vias, entre terapeuta e paciente. O nome "tempo no chão" se dá porque essas interações devem acontecer em ambientes seguros e apropriados, normalmente no chão, onde o adulto que ministra a sessão pode se abaixar e ficar no mesmo nível que a criança, para facilitar o contato olho no olho (CLIA PSICOLOGIA, 2020).

E por fim, a medicação deve ser administrada por meio de prescrição e acompanhamento médico, uma vez que até o momento não existe uma medicação específica para o espectro. É utilizada quando existem comorbidades e seus sintomas afetam o dia a dia do indivíduo, sendo necessário que o médico saliente os efeitos colaterais das medicações, e deixe claro o que se deve esperar atingir e qual o prazo para que se perceba os efeitos aguardados (MELLO, 2013). 


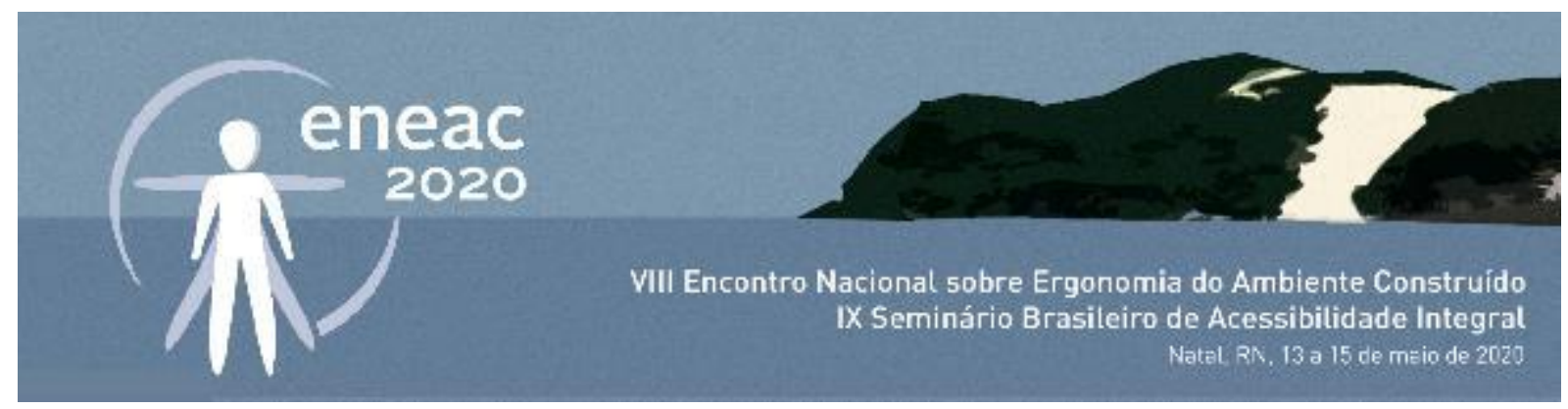

\title{
4 O AUTISMO E O ESPAÇO FÍSICO
}

Os indivíduos com o Transtorno do Espectro Autista (TEA) podem ter um déficit no mecanismo responsável por unir pensamentos e ações. Diante desse fato, eles possuem uma capacidade de interação comprometida, tanto com as pessoas, quanto com o seu entorno, em comparação ao indivíduo neurotípico.

\subsection{Arquitetura inclusiva}

O termo "acessibilidade" possui diferentes significados para os diversos especialistas do mundo. Nas normas brasileiras, a acessibilidade pressupõe a "possibilidade e a condição de utilizar, com segurança e autonomia, os edifícios, o espaço, o mobiliário e os equipamentos urbanos e elementos" (ABNT, 2015).

Atualmente é uma realidade entre os projetistas pensar sobre a acessibilidade ao projetar rampas, calçadas e acessos que permitem o ir e vir de todas pessoas, sem restrições por conta da mobilidade física. Porém, ainda não se tem tantas informações no que tange à sensibilidade que os autistas possuem de maneira mais intensa ou menos intensa, o que acaba interferindo nas relações que eles têm com o espaço em que convivem.

Partindo dessa premissa, Antunes (2007), afirma que uma arquitetura que não foi contemplada para estimular o desenvolvimento dessas crianças, pode inclusive prejudicar sua evolução.

\begin{abstract}
Nossos corpos e movimentos estão em constante interação com o ambiente; o mundo e a individualidade humana se redefinem um ao outro constantemente. A percepção do corpo e a imagem do mundo se tornam uma experiência existencial contínua; não há corpo separado de seu domicílio no espaço, não há espaço desvinculado da imagem inconsciente de nossa identidade pessoal perceptiva (PALLASMAA, 2011, p. 38);
\end{abstract}

Mas o que se vê na realidade desse tipo de ambiente, é que o aluno com deficiência tem que se adequar aos projetos das escolas brasileiras. Sendo que o padrão de inclusão deveria ser implantado nesses espaços já na concepção do projeto e na sociedade como um todo, pois a educação inclusiva precisa ser entendida como um ambiente apto à diversidade (ANTUNES, 2007).

Segundo Tuan (1983, p.119), "o meio ambiente construído, como a linguagem, tem o poder de definir e aperfeiçoar a sensibilidade. Pode aguçar e ampliar a consciência. Sem arquitetura, os sentimentos sobre o espaço permanecem difusos e fugazes". $O$ autor afirma ainda que a forma construída tem o poder de aumentar a consciência do sentido de interior e exterior, intimidade e exposição, vida privada e espaço público.

O conceito de acessibilidade pode ser dividido em seis dimensões. Sassaki (2006) considera todas as dimensões como importantes, complementares e indispensáveis para o processo de inclusão efetivo e de qualidade. Dessa maneira, dentro do ambiente educacional, as dimensões propostas são detalhadas da seguinte forma (SASSAKI, 2006):

- Arquitetônica: eliminação das barreiras físicas que dificultam o acesso aos ambientais. 0 acesso e adaptações físicas dos espaços, desde a entrada da escola até as salas de aula, bem como em toda a área de circulação deve ser assegurado.

- Comunicacional: eliminação das barreiras de comunicação interpessoal e escrita. A utilização de recursos diversos, línguas e linguagens que venham a facilitar a comunicação, devem ser asseguradas no processo educacional; 


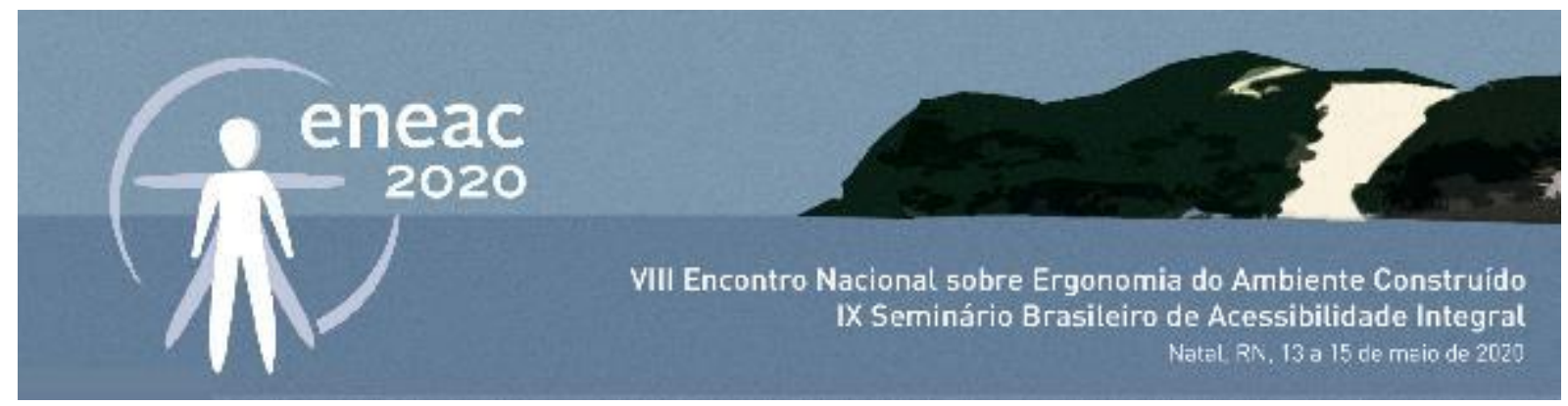

- Metodológica: eliminação das barreiras nos métodos pedagógicos e técnicas de estudos.

- Instrumental: eliminação das barreiras nos instrumentos, utensílios e ferramentas pedagógicas. A adaptação de materiais de forma que todos os indivíduos poderão utilizá-los nos momentos de aprendizagem.

- Programática: eliminação das barreiras ocultas em políticas públicas (leis, decretos, portarias e resoluções) que possam impedir ou dificultar a participação plena de todos os indivíduos, com ou sem deficiência, na vida escolar.

- Atitudinal: eliminação de atitudes preconceituosas, estigmatizantes, estereotipadas e discriminatórias. A promoção de atividades na escola e seu entorno promovem a sensibilização, conscientização e estimulam a convivência dos indivíduos partícipes do processo educacional.

Mostafa (2008), sequenciou em suas pesquisas sete requisitos fundamentais que influenciam nesses ambientes internos com o objetivo de criar alguns preceitos para os projetos arquitetônicos inclusivos que são: os acústicos, o sequenciamento espacial, o espaço de fuga, a compartimentalização, as transições, o zoneamento sensorial e segurança. Estes requisitos serão explicados a seguir, seguindo a conceituação de Mostafa (2008).

Em relação aos preceitos acústicos é comum os autistas possuírem uma grande sensibilidade auditiva, por isso o espaço acústico deve ser estudado de forma a reduzir os ruídos, os ecos e a reverberação.

No que tange o sequenciamento espacial, trata-se a questão da organização lógica dos espaços, configurados de acordo com a programação horária dos usos, fazendo com que a fluidez dos espaços seja livre e tranquila entre uma atividade e outra, sem interrupções.

O espaço de fuga diz respeito ao local onde os autistas poderão descansar e relaxar um pouco da superestimulação que vivenciam nos outros ambientes. Esses espaços precisam estar posicionados em uma área tranquila do projeto, devem ser sensorialmente neutros e não precisam ser ambientes grandes, uma vez que sua função é apenas abrigar a criança dos excessos de estímulos.

Quanto a compartimentação, a função de cada ambiente é traduzida arquitetonicamente de forma clara e adequada, sendo trabalhada apropriadamente a qualidade sensorial que lhe é proposta, como pode ser observado neste ambiente do Centro para Autismo e Desenvolvimento Cerebral (Center of Autism and the Developing Brain - CADB), de Nova lorque, apresentado na Figura 2.

Em relação aos preceitos das áreas de transições, são estes onde a criança se reequilibra e recarrega suas energias sensoriais, quando for necessário mudar de um estímulo para outro. E é no zoneamento sensorial que os ambientes são baseados em zonas funcionais ordinárias e generalizantes.

Por fim, ainda segundo Mostafa (2008), é necessário um cuidado especial com a segurança, pois as crianças dentro do espectro autista possuem uma relação alterada com seu entorno imediato. 


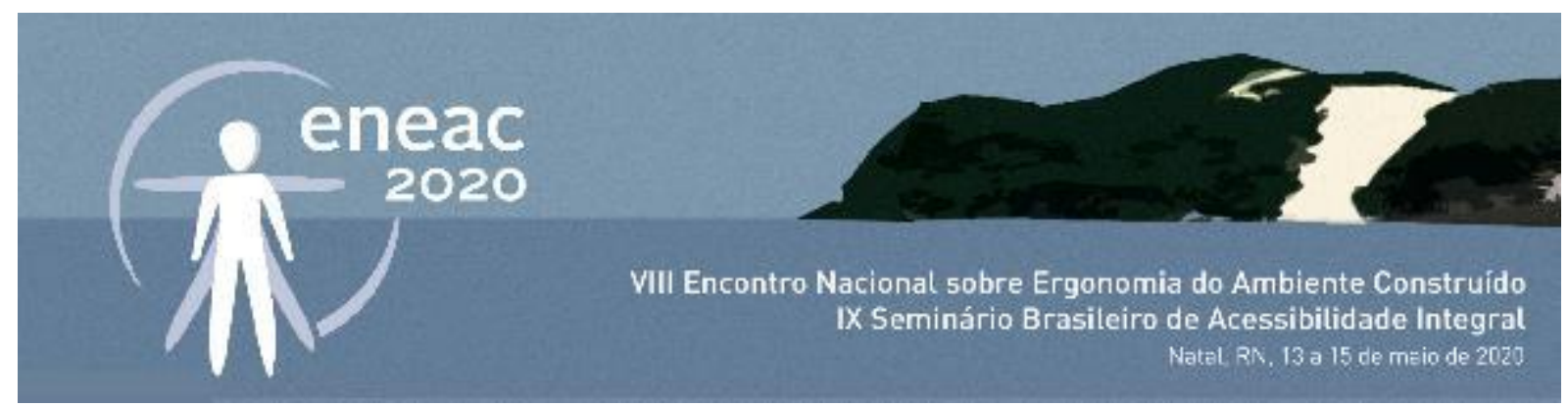

Figura 2 - As cores auxiliando na compartimentação do ambiente - Centro para Autismo e Desenvolvimento Cerebral, Nova lorque.

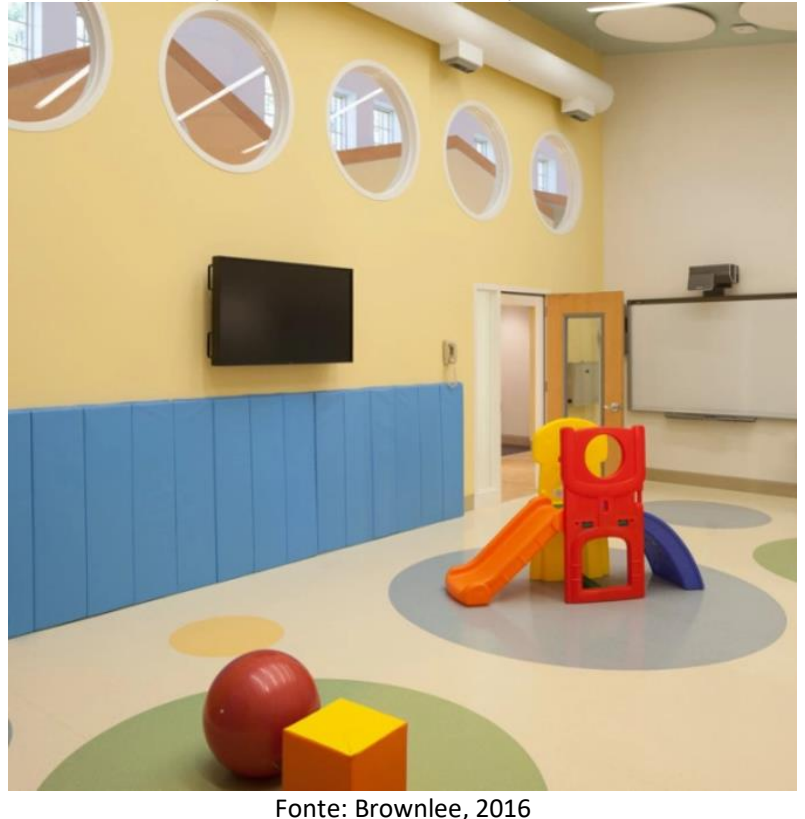

\subsection{Ambientes Terapêuticos}

As formas de se comunicar e de se expressar das pessoas podem ser acionadas pelos estímulos fornecidos pelos ambientes que elas frequentam. Bosa (2001) deixa claro que a prática nas terapias e na integração sensorial têm resultados excelentes, principalmente, em crianças que possuem uma série de limitações de desenvolvimento e aprendizagem, incluindo o autismo e alguns outros distúrbios de desenvolvimento e comportamento.

Normalmente, os tratamentos clássicos são desenvolvidos dentro de um espaço terapêutico que foi criado e pensado para que o terapeuta consiga apresentar aos pacientes, os desafios sensoriais e de movimentos, intensificando a dificuldade progressivamente ao longo do acompanhamento. Sendo esse tipo de intervenção rodeado por um meio lúdico, onde a criança é incitada a produzir ideias para o desenvolvimento dos exercícios e atividades propostas, como também incentivada a desenvolver novos desafios, trabalhando sempre a confiança e a competência de cada indivíduo (LAUREANO, 2017).

Laureano (2017) também observa que os espaços terapêuticos sensoriais neutros, exemplificado no ambiente apresentado na Figura 3, conseguem proporcionar a auto regulação e a mudança positiva, por trabalharem com os estímulos da quebra de rotina e da modulação sistemática, que são características típicas das crianças e pessoas portadores do espectro autista.

O mesmo autor ainda destaca que alguns elementos conseguem contribuir para que o ambiente proporcione incentivos para os sistemas sensoriais dos seus usuários, como a iluminação e as cores. Essas características também podem ser observadas no Centro para Autismo e Desenvolvimento Cerebral de Nova lorque (Figura 4). 


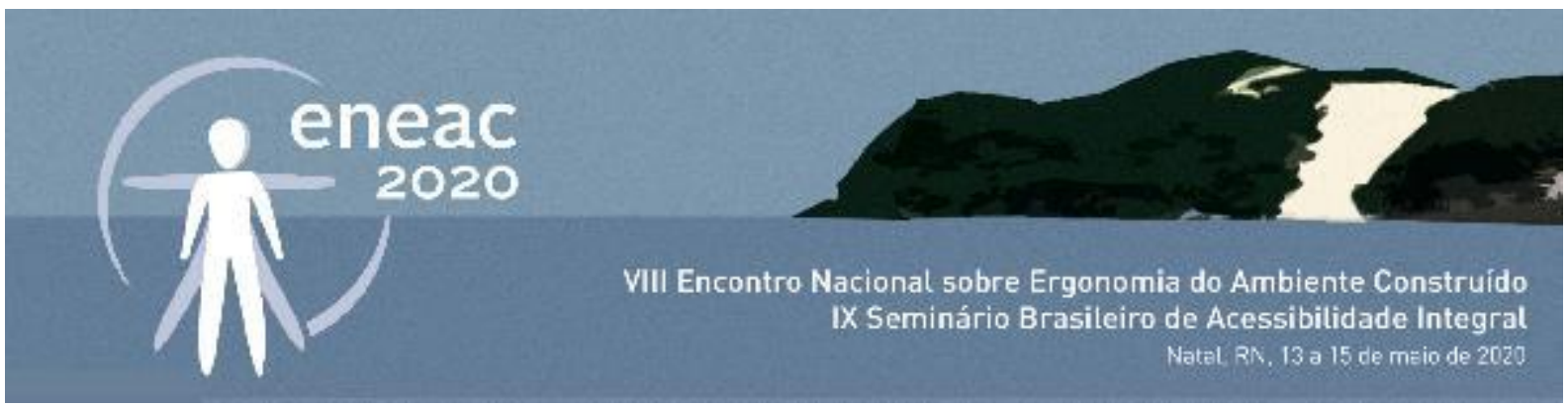

Figura 3 - Espaço infantil sensorial neutro - Centro para Autismo e Desenvolvimento Cerebral, Nova lorque.

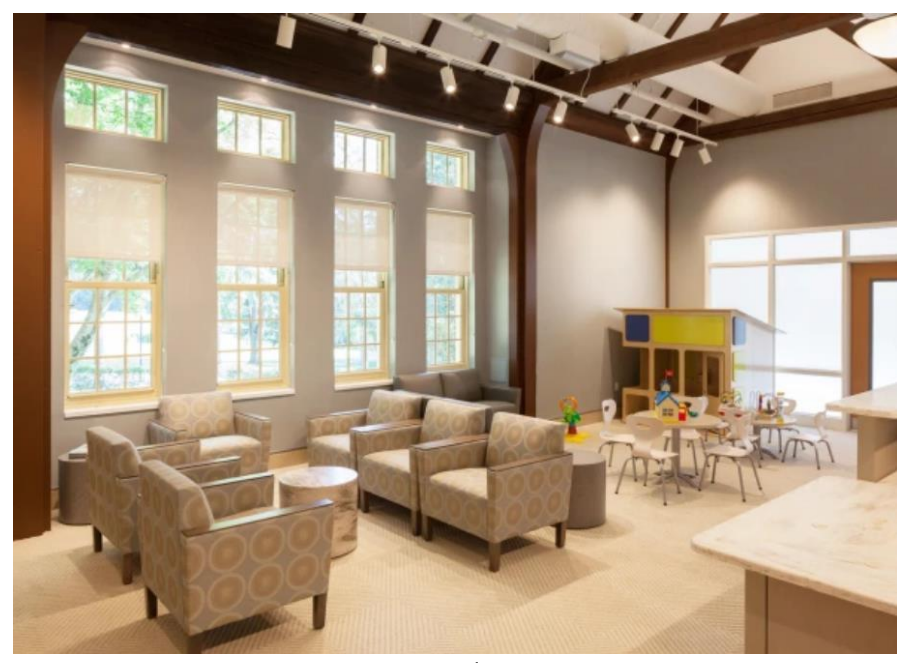

Fonte: Brownlee, 2016
Figura 4 - Espaço infantil sensorial, utilizando luzes e cores - Centro para Autismo e Desenvolvimento Cerebral, Nova Iorque.

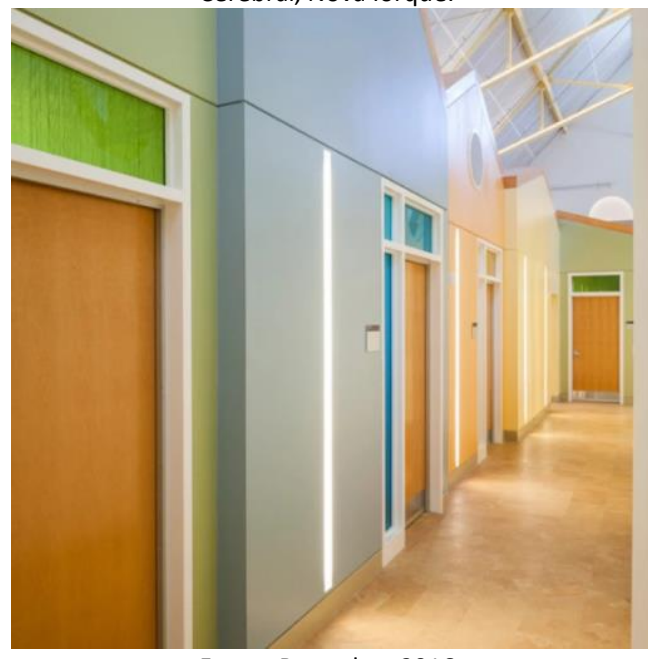

Fonte: Brownlee, 2016

Segundo Bosa (2001), deve-se planejar o tratamento de uma pessoa dentro do espectro autista de acordo com sua etapa de vida. Se criança, as terapias da fala e de comportamento, que influenciam na interação social devem ser prioridades. Sendo este um tratamento multidisciplinar, envolve intervenções psicoeducacionais, desenvolvimento da linguagem e comunicação, e sem esquecer de apoio, acompanhamento e orientação familiar. Essa equipe de acompanhamento multidisciplinar, composta normalmente por psicólogos, pedagogos, fonoaudiólogos, terapeutas ocupacionais, fisioterapeutas e educadores físicos, precisa avaliar e desenvolver um programa de intervenção orientado a satisfazer as necessidades particulares de cada indivíduo (BOSA, 2001).

Organizar o espaço em áreas e cantos temáticos é uma alternativa que possibilitará a interação das crianças com diferentes materiais, permitindo-lhes um entendimento de uso coletivo do espaço, onde ao mesmo tempo são possíveis escolha individuais e grupais que certamente favorecem também a construção de sua autonomia. (REDIN, MÜLLER, REDIN, 2007, p. 104)

De acordo com o Orrú (2007), o grande objetivo de realização da atividade terapêutica, é estimular a criança com dificuldades de interação social e na comunicação, para que ela tenha vontade de interagir com o profissional e com outras pessoas dentro do seu ambiente. Claro que isso tudo precisa ser prazeroso para que a criança consiga aprender e a desenvolver novas habilidades. E nesse seguimento, para os profissionais que trabalham nesse setor, as atividades terapêuticas sensoriais possuem o objetivo de proporcionar o desenvolvimento das habilidades emocionais, sociais, cognitivas e motoras.

\subsection{Elementos de Estimulação Sensorial}

A ambiência (PALLASMAA, 2011) é composta por elementos que interagem e afetam o comportamento humano e os ambientes terapêuticos sensoriais são capazes de proporcionar ao indivíduo o estimulo e o equilíbrio da integração sensorial.

Podemos citar como elementos sensoriais, segundo Laureano (2017): 


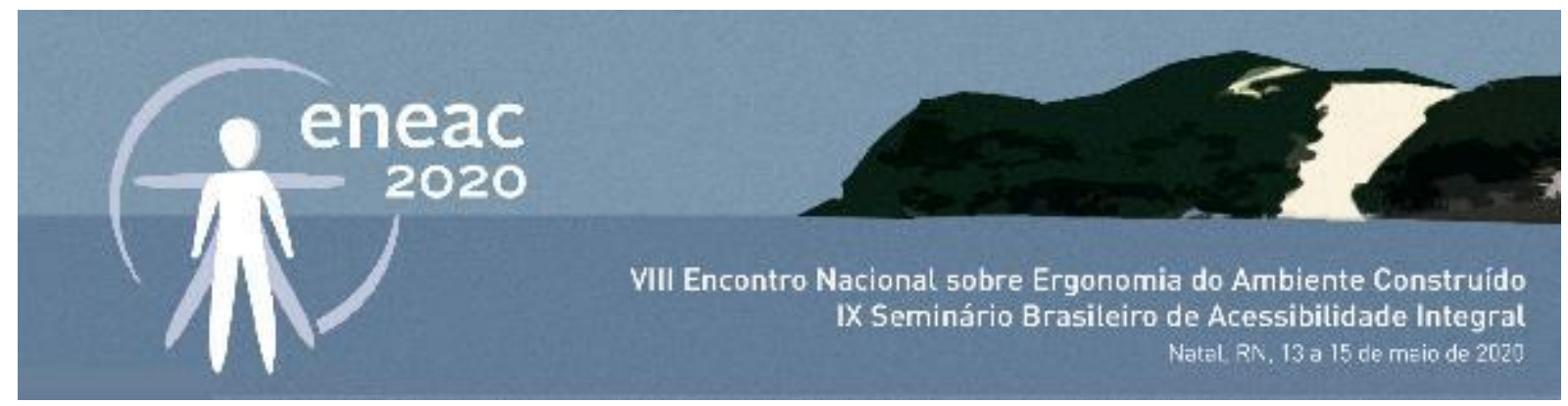

- Multifuncionalidade aos ambientes internos: espaços que promovam a atividade intelectual e incentivem o relaxamento. Para isso é importante que as estimulações possam ser controladas, despertando as potencialidades de cada indivíduo, através de um atendimento individualizado.

- Texturas e cores: possibilitar um trabalho tátil e visual, que colabore para o desenvolvimento da consciência corporal e cognitiva do autista. Podem estar associados à identidade visual, especializados a partir da criação de caminhos evidentes, códigos de cores, formas simples e identificações a partir de figuras.

- Iluminação: proporcionar uma interação física e lúdica das crianças, além de possibilitar atividades mais focadas ou descontraídas a partir da configuração da luz. Além da iluminação cênica, é possível utilizá-la através de elementos diversos, com a proposta de oferecer estímulos que despertam e liberam as percepções sensoriais.

- Mobiliário: deve contribuir com a questão da ergonomia, mas também é importante que tenha a possibilidade de dificultar o acesso de alguns equipamentos para os usuários.

Além disso podem ser utilizados como forma de promover nichos ou barreiras, destacando assim o espaço pessoal, seja ele individual ou coletivo.

- Layout: precisa estabelecer um espaço seguro e funcional a partir da flexibilidade. Alguns elementos como painéis e divisórias moveis, possibilitam o uso dos espaços de diferentes formas, podendo se moldar a partir da necessidade de uso individual ou coletivo por diferentes profissionais.

- Amplidão: possibilita a adaptabilidade do ambiente e permite o ajuste das distâncias interpessoais. A flexibilidade está relacionada com esse fator, que pode ser promovido a partir dos elementos de estimulação sensorial (iluminação, materiais, diferenciação de pés-direitos, e outros).

- Identidade visual e legibilidade: são importantes elementos de composição do espaço para estimular a independência das pessoas com TEA, pois como possuem uma ótima memória visual, promover essas informações visuais concretas torna-se um importante estímulo à autonomia (BEAVER, 2006).

- Espaços ao ar livre: promovem uma parte essencial da consciência ambiental do indivíduo, podendo proporcionar a sensação de independência. Além disso, Beaver (2006) cita que paisagens naturais com a utilização de vegetação proporcionam relações sensoriais, seja ela de forma visual ou apropriativa.

\subsection{Elementos Construtivos}

A maneira distinta das pessoas com autismo perceberem o ambiente construído desafia a maneira predominante de pensar e de se projetar os espaços. No entanto, as características percebidas por eles podem ser transformadas em algo que todos na comunidade poderiam facilmente transformar em pontos fortes (BEAVER 2006).

Espaços dinâmicos podem estar associados a multifuncionalidade, como nas circulações, que podem agregar funções como áreas de estar. Utilizar paredes curvas além de proporcionar um espaço dinâmico, pode ser uma estratégica para auxiliar os autistas no deslocamento do edifício, pois eles 


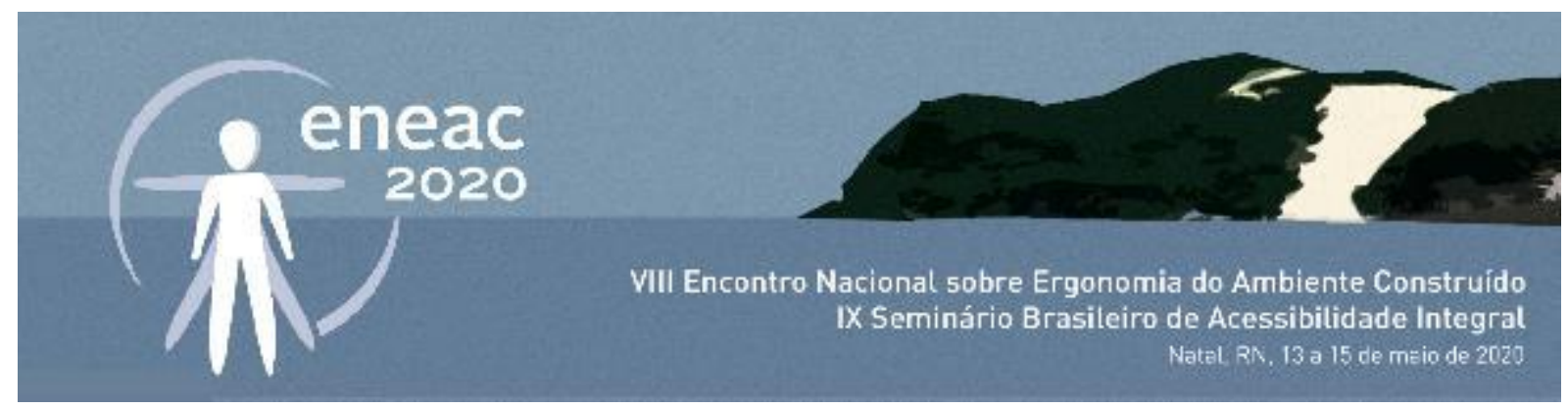

procuram evitar esquinas repentinas (MACHADO 2012).

A relação interno-externo, segundo Machado (2012), auxilia no desenvolvimento da consciência corporal, cognitiva e proporciona diferentes percepções e relações entre o meio e o usuário. Seja por meio da paisagem urbana do entorno, ou da criação de paisagens naturais através do paisagismo.

O zoneamento também é um item importante no processo de evolução projetual, sendo melhor pensado, conforme Machado (2012), nas percepções sensoriais do usuário, ao invés de serem estipulados por zonas funcionais generalizantes. O autor ainda defende que o zoneamento seja simples e de fácil compreensão, proporcionando maior autonomia aos usuários.

Quanto a volumetria, Laureano (2017) aborda que o volume arquitetônico pode ser constituído de forma livre, desde que não interfira na funcionalidade e acessibilidade do espaço, sendo importante sempre buscar estimular a autonomia dos autistas, seja objetiva ou subjetivamente. Já no que se refere à utilização das cores, o autor deixa claro que podem estar associadas a uma importante função do edifício, se utilizadas de forma coerente com os estímulos que se pretende, visto que existem cores neutras, calmantes, perturbadoras, estimulantes, entre outras.

Laureano (2017), ainda destaca a utilização de superfícies lisas e resistentes. Contudo, é importante explorar a materialidade de forma harmônica, possibilitando diferentes texturas e percepções sensoriais, mas sem sobrecarregar o ambiente.

\subsection{Diretrizes Projetuais}

A partir da revisão de literatura realizada e da experiência pessoal de uma das autoras, citadas anteriormente, foram elencadas algumas características conceituais essenciais, como:

- Planejamento: padrões generosos de espaços; setorização e layout planejados.

- Inclusão: acessibilidade (ABNT, 2015); treinamento das habilidades de vida diária; e possibilitar a participação da família no tratamento.

- Simplicidade e Clareza: forma arquitetônica simples; clareza no layout; zoneamento prático; e evitar a poluição visual com excesso de cores e formas.

- Integração social: salas de baixo estímulo sensorial e com distrações controláveis; promover o relaxamento e melhorar a coordenação, desenvolver tolerância aos estímulos que incomodam, promover oportunidades multissensoriais.

- Equilíbrio: evitar o estresse e ansiedade; permitir a retomada do autocontrole; e se livrar de distrações e estímulos.

- Segurança e Proteção: espaços externos definidos; limites físicos e visuais; evitar arestas pontiagudas.

Já no que diz respeito às características construtivas, têm-se:

- Acústica: materiais aconchegantes; pisos emborrachados; forros de gesso acartonado e manta acústica; paredes com acabamentos diversos.

- Iluminação: uso de dimmers e controladores de intensidade da luz artificial; aproveitamento máximo da luz natural; sempre que possível; utilizando janelas e aberturas amplas. 


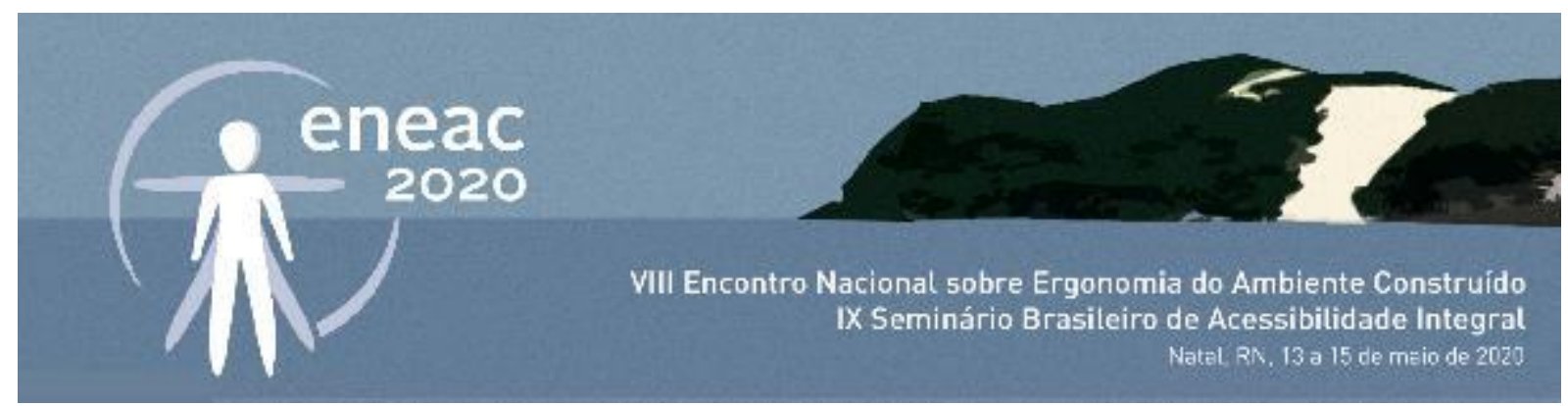

- Ventilação: trabalhar as aberturas para valorizar a ventilação natural e cruzada, possibilitando espaços bastante ventilados.

- Durabilidade e Manutenção: materiais acessíveis de fácil reparação.

Apresentadas as recomendações para projetos mais humanos e que melhor acolham as pessoas com TEA, nota-se que o objetivo é proporcionar a qualidade espacial indispensável à realização das atividades propostas pelo ambiente, mas assumindo uma característica versátil, capaz de atender as singularidades sensoriais e de compreensão de cada indivíduo.

\section{CONSIDERAÇÕES FINAIS}

Sendo a proposta dessa pesquisa compreender como a arquitetura pode contribuir para o desenvolvimento das pessoas do espectro autista a partir das especificidades que circundam o transtorno, percebe-se o TEA como campo fecundo para novas explorações no que tange a imaginação e aspectos sensoriais.

Com essa investigação arquitetônica, propõe-se experimentações mais direcionadas e relativas ao vínculo entre espaço e indivíduo, conduzindo esses resultados para perspectivas mais amplas. Assim, fundamentados na identidade sensorial e pessoal, os ambientes físicos irão exercer uma função importante e propícia ao convívio e novos comportamentos das pessoas com TEA.

Para tanto é fundamental compreender o debate entre permanência e mudança que transpassa o criar construtivo. Distante de anunciar somente uma solução para essas questões, o ambiente deve se estabelecer no curso constante de necessidades pessoais, incluindo novos propósitos e funcionalidades, que representam as mais diversas formas de compreender a realidade humana.

\section{AGRADECIMENTOS}

Os autores agradecem à Faculdade Pitágoras de Guarapari pelo incentivo à realização desta pesquisa.

\section{REFERÊNCIAS}

AMORIM, L. C. D. Autismo: Tratamento. In: ASSOCIAÇÃO DE AMIGOS DO AUTISTA (AMA). São Paulo. Disponível em: https://www.ama.org.br/site/autismo/tratamento/. Acesso em: 5 fev. 2020.

ANTUNES, K. C. V. Uma leitura sociológica da construção do espaço escolar à luz do paradigma da educação inclusiva. Dissertação (Mestrado em Educação) - Faculdade de Educação, Universidade do Estado do Rio de Janeiro, Rio de Janeiro, 2007.

ASSOCIAÇÃO BRASILEIRA DE NORMAS TÉCNICAS. ABNT NBR 9050: acessibilidade a edificações, mobiliário, espaços e equipamentos urbanos. Rio de Janeiro: ABNT, 2015.

ASSOCIAÇÃO DE AMIGOS DO AUTISTA (AMA). Definição: transtornos do espectro do autismo. Nota OMS de abril de 2017 Traduzido e Adaptado por Vinicius Aguiar. São Paulo, 2017. Disponível em: https://www.ama.org.br/site/autismo/ definicao/. Acesso em: 5 fev. 2020.

BEAVER, C. Designing Environvents for Children and Adults with ASD. Autism Safari 2006: 2nd World Autism Congress \& Exhibition Autism Spectrum Disorder, 2006. Disponível em: 


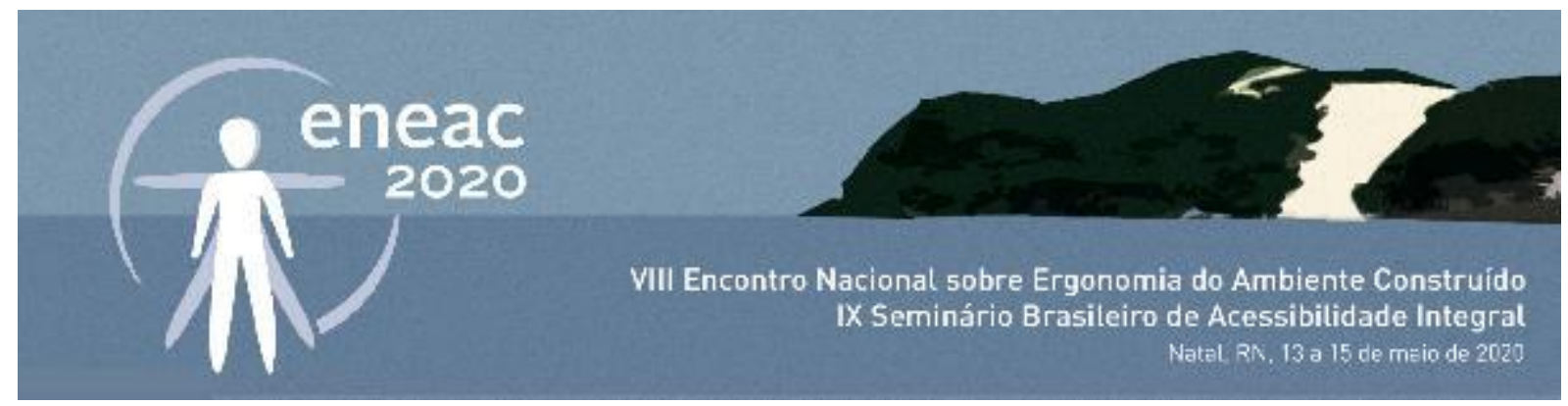

https://www.autism.org.uk/ /media/nas/documents/working-with/creating-autism-friendlyplaces/designing_environments_for_children_adults_with_asd.ashx?la=en-gb. Acesso em: 5 fev. 2020.

BOSA, C. A. As Relações entre Autismo, Comportamento Social e Função Executiva. Psicologia: Reflexão e Crítica. Porto Alegre: Universidade Federal do Rio Grande do Sul. Porto Alegre, 2001, 14(2), p. 281-287. Disponível em: http://www.scielo.br/pdf/prc/v14n2/7855.pdf. Acesso em: 5 fev. 2020.

BROWNLEE, J. How to design for autism. In: FastCompany. Mai. 2016. Disponível em: https://www.fastcompany.com/3054103/how-to-design-for-autism. Acesso em: 5 fev. 2020.

CLIA PSICOLOGIA - Saúde e Educação. Autismo - Método D.I.R. ${ }^{\circledR}$ Floortime ${ }^{\mathrm{TM}}$. Site. São Paulo. Disponível em: https://cliapsicologia.com.br/autismo-metodo-d-i-r-floortime/. Acesso em: 5 fev. 2020.

GRANDIN, T. O cérebro autista: pensando através do espectro. Tradução: Maria Cristina Torquilho Cavalcanti. Rio de Janeiro: Record, 2015.

LAUREANO, C. J. B. Recomendações Projetuais para ambientes com atendimento de terapia sensorial direcionados a crianças com autismo. Dissertação (Mestrado em Arquitetura e Urbanismo) - Faculdade de Arquitetura e Urbanismo, Universidade Federal de Santa Catarina, Florianópolis, 2017.

MACHADO. E. S. Relações entre ambientes externos e internos em centros de reabilitação motora: um estudo na Associação de Assistência à criança deficiente de Nova Iguaçu - RJ. 2012. Tese (Doutorado em Arquitetura e Urbanismo) - Faculdade de Arquitetura e Urbanismo, Universidade do Estado do Rio de Janeiro, Rio de Janeiro, 2012.

MELLO, A. M. S. R. Autismo: guia prático. 7. ed. São Paulo: AMA; Brasília: CORDE, 2007. Disponível em: http://www.autismo.org.br/site/images/Downloads/7guia\%20pratico.pdf. Acesso em: 5 fev. 2020.

MELLO, A. M.; HO, H.; DIAS, I.; ANDRADE, M. Retratos do Autismo no Brasil. São Paulo: AMA, 2013. Disponível em: https://www.autismo.org.br/site/images/Downloads/RetratoDoAutismo-20131001.pdf. Acesso em: 5 fev. 2020.

MOSTAFA, M. An architecture for autism: concepts of design intervention for the autistic user. International Journal of Architectural Research - IJAR, v. 2, n. 1, p. 189-211, 2008. Disponível em:

https://www.researchgate.net/publication/26503573_An_An_Architecture_for_Autism_ Concepts_of_Design_Intervention_for_the_Autistic_User. Acesso em: 5 fev. 2020.

ORRÚ, S. E. Autismo, linguagem e educação: interação social no cotidiano escolar. Rio de Janeiro: Wak Editora, 2007.

PALLASMAA, Juhani. Os olhos da pele: a arquitetura e os sentidos. Porto Alegre: Bookman, 2011.

REDIN, E.; MÜLLER, F.; REDIN, M. (Orgs.). Infâncias: cidades e escolas amigas das crianças. Porto Alegre: Mediação, 2007.

RUSSO, F. Graus de autismo - importante saber. NeuroConecta. 20 set. 2017. Disponível em: https://neuroconecta.com.br/graus-de-autismo-importante-saber/. Acesso em: 5 fev. 2020.

SASSAKI, R. K. Inclusão: Construindo uma sociedade para todos. Rio de Janeiro: WVA, 1997. Disponível em: https://www.passeidireto.com/arquivo/32657552/sassaki-romeu-kazuma-inclusao-construindo-uma-sociedade-paratodos. Acesso em: 5 fev. 2020.

TUAN, Y. Espaço e Lugar: a perspectiva de experiência. Tradução de Lívia de Oliveira. São Paulo: DIFEl, 1983. 